ORNL/TM-13456

\section{OAK RIDGE NATIONAL LABORATORY}

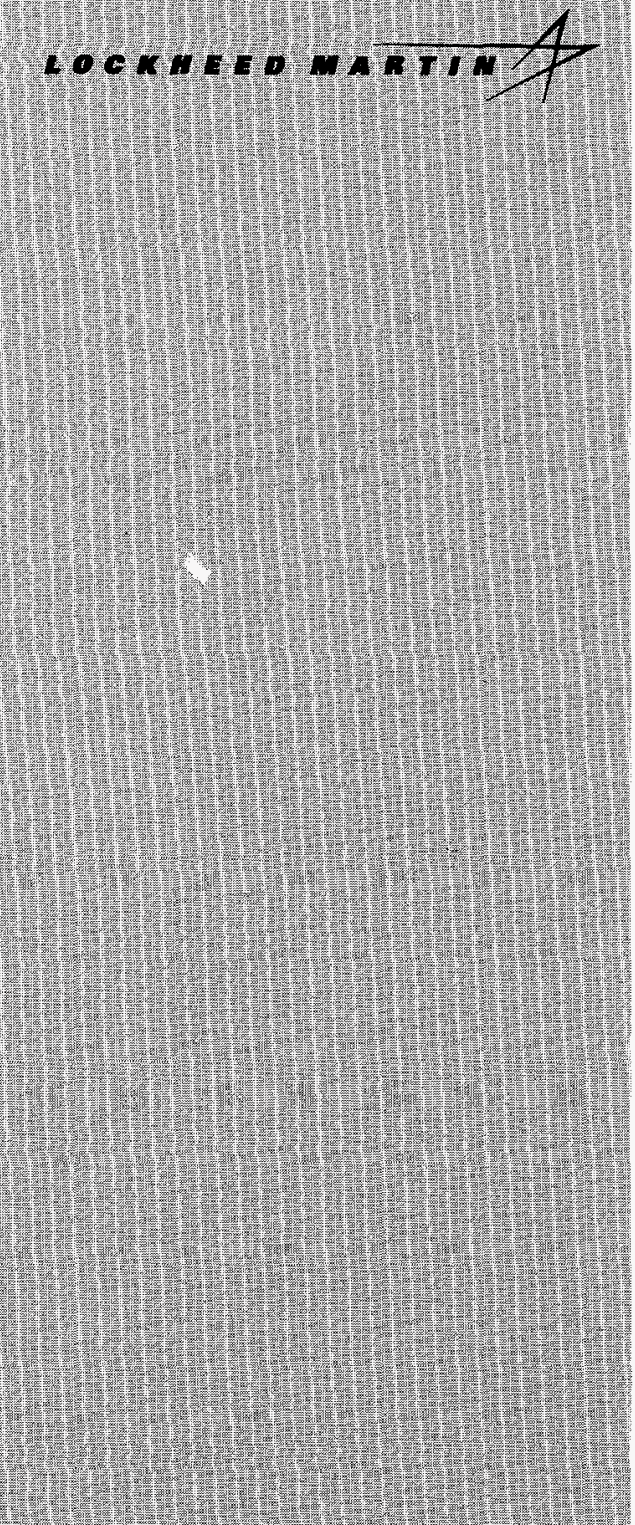

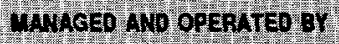
LOCKHEEO WARIN EMERG RESEARCH CORPOR MUIOY FOA THE UMTED STATES DEPARTUET OF ENERET

\title{
Instrument Calibration Plan of the Technical Support Section
}

\author{
K. L. Allison \\ B. C. Davis \\ H. E. Smith \\ J. O. Hylton \\ W. L. Robbins
}
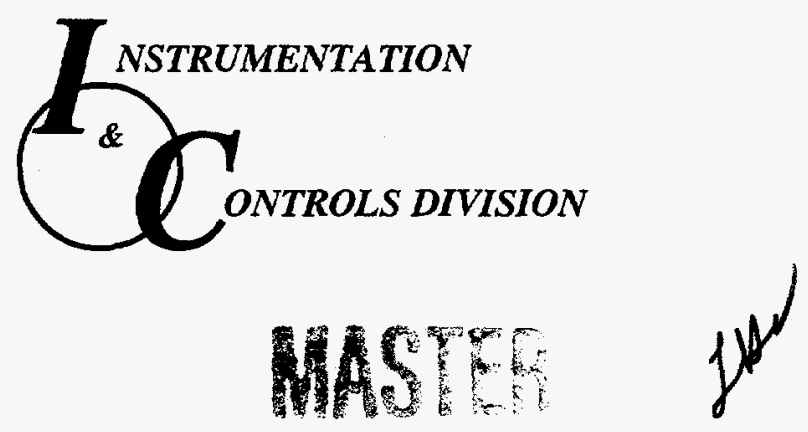

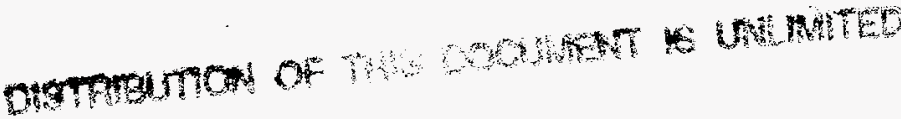


This report has been reproduced directly from the best available copy.

Available to DOE and DOE contractors from the Office of Scientific and Technical Information, P. O. Box 62, Oak Ridge, TN 37831; prices available from (423) 576-8401, FTS 626-8401.

Available to the public from the National Technical Information Service, U.S. Department of Commerce, 5285 Port Royal Road, Springfield, VA 22161.

This report was prepared as an account of work sponsored by an agency of the United States Government. Neither the United States Government nor any agency thereof, nor any of their employees, makes any warranty, express or implied, or assumes any legal liability or responsibility for the accuracy, completeness, or usefulness of any information, apparatus, product, or process disclosed, or represents that its use would not infringe privately owned rights. Reference herein to any specific commercial product, process, or service by trade name, trademark, manufacturer, or otherwise, does not necessarily constitute or imply its endorsement, recommendation, or favoring by the United States Government or any agency thereof. The views and opinions of authors expressed herein do not necessarily state or reflect those of the United States Government of any agency thereof. 


\section{DISCLAIMER}

Portions of this document may be illegible electronic image products. Images are produced from the best available original document. 


\title{
Instrumentation and Controls Division \\ INSTRUMENT CALIBRATION PLAN OF THE TECHNICAL SUPPORT SECTION
}
K. L. Allison
B. C. Davis
H. E. Smith
J. O. Hylton
W. L. Robbins

Date Published: June 1997

\author{
Prepared by \\ OAK RIDGE NATIONAL LABORATORY \\ Oak Ridge, Tennessee 37821-6285 \\ managed by \\ LOCKHEED MARTIN ENERGY RESEARCH CORP. \\ for the \\ U.S. DEPARTMENT OF ENERGY \\ under contract DE-AC05-96OR22464
}




\section{TABLE OF CONTENTS}

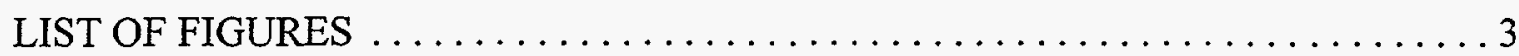

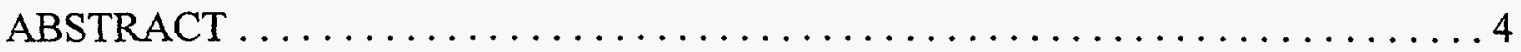

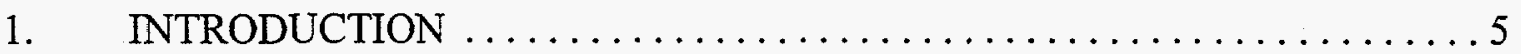

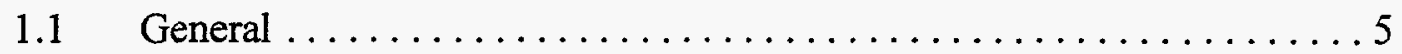

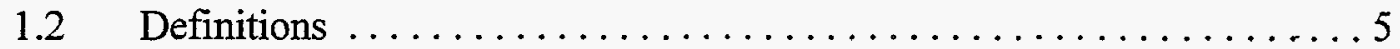

2. PROGRAM ORGANIZATION $\ldots \ldots \ldots \ldots \ldots \ldots \ldots \ldots \ldots \ldots$

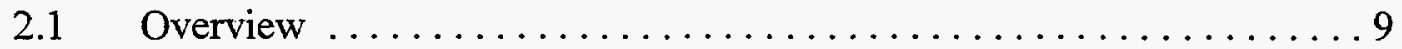

2.2 Program Policy and Direction $\ldots \ldots \ldots \ldots \ldots \ldots \ldots \ldots \ldots$

2.3 Calibration Program Elements . . . . . . . . . . . . . . . . 9

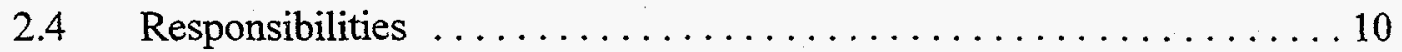

2.4.1. Technical Support Section .................... 10

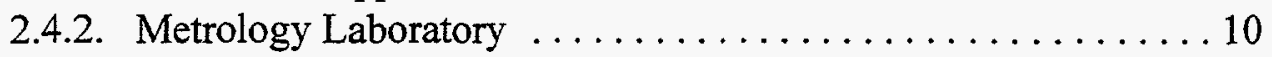

2.4.3. Shop Supervisor/Technical Support $\ldots \ldots \ldots \ldots \ldots \ldots \ldots$

2.4.4. Technician ...............................

2.4.5. User/Task Leader $\ldots \ldots \ldots \ldots \ldots \ldots \ldots \ldots \ldots \ldots \ldots$

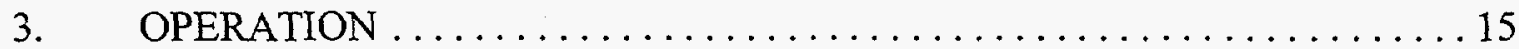

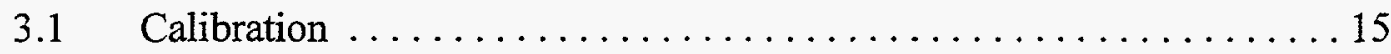

3.2 Exceptions to Periodic Calibration Requirements ............ 16

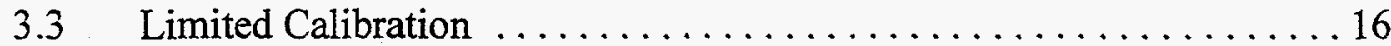

3:3.1 Limited Shop Capability . . . . . . . . . . . . . . . . 16

3.3.2 Limited User Requirements . . . . . . . . . . . . . . . . 16

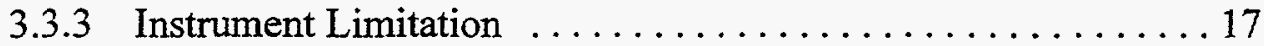

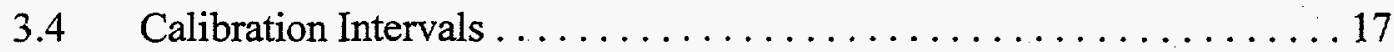

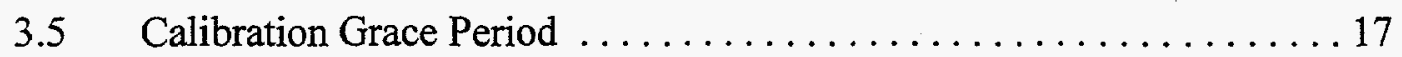

3.6 Calibration Deviations ........................... 18

3.7 Care of Measuring and Test Equipment $\ldots \ldots \ldots \ldots \ldots \ldots \ldots \ldots$

3.8 Measuring and Test Equipment Warranties ................ 19

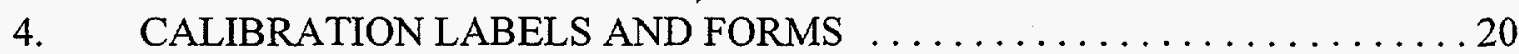

4.1 Preparation and Use of Calibration Forms and Labels $\ldots \ldots \ldots \ldots 20$

4.2 Measuring and Test Equipment Calibration Label ............ 20

4.3 Placement of Calibration Labels $\ldots \ldots \ldots \ldots \ldots \ldots \ldots \ldots \ldots . \ldots \ldots$

4.4 Calibration Record ............................... 21

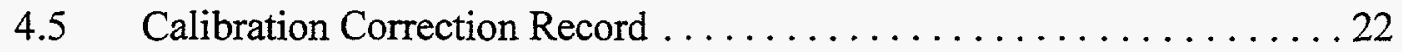

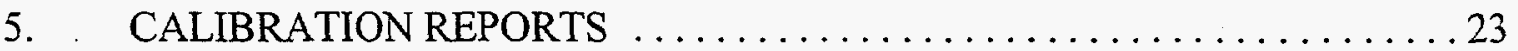




\section{LIST OF FIGURES}

1. Calibration status label $\ldots \ldots \ldots \ldots \ldots \ldots \ldots \ldots \ldots \ldots \ldots$

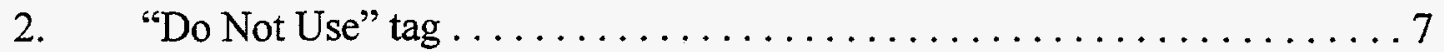

3. Measurement traceability of the Calibration Program $\ldots \ldots \ldots \ldots \ldots 11$

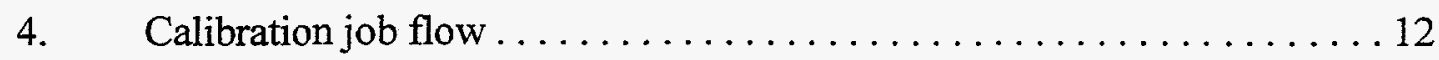

5. Flow of the calibration process after the custodian decides that $M \& T E$ requires calibration $\ldots \ldots \ldots \ldots \ldots \ldots \ldots$

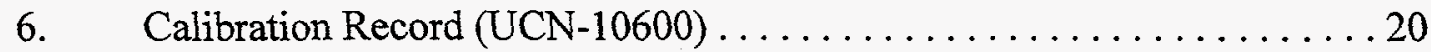




\begin{abstract}
This document describes the Calibration Program for the Instrumentation and Controls Division's Technical Support Section (TSS). The implementation of the program is the responsibility of TSS; however, determining whether or not equipment is is to calibrated is the responsibility of the equipment's custodian or user.

The Calibration Program is a planned, systematic schedule of actions necessary to provide confidence that equipment used to make measurements or quality judgments meets established technical requirements and that its performance is traceable to nationally recognized standards. It is imperative that all parties maintain timely and effective dialogue to ensure that the process is adequate to meet the needs of Oak Ridge National Laboratory (ORNL).
\end{abstract}

It is especially important to place this guidance in the proper context. ORNL instrumentation support at the shop and facility level is the primary application. Lockheed Martin Energy Research Corporation (LMER) and site policy provide the umbrella guidance for overall measuring and test equipment support. 


\section{INTRODUCTION}

This document describes the methods and procedures for management of the ORNL Instrumentation and Controls (I\&C) Division's Technical Support Section (TSS) Calibration Program. All personnel who have responsibility for calibration of equipment shall be familiar with the Calibration Program described in this document.

\subsection{General}

The primary function of the TSS Calibration Program is to ensure the measurement integrity of all instruments used to provide quantitative or qualitative data to meet program objectives and to ensure safe, reliable, cost-effective, and timely operation.

The TSS Calibration Program addresses measurement standards and equipment technical personnel, TSS work centers, measurement equipment users, calibration data, and integrated planning, combined in a structured program to ensure the reliability and accuracy of instruments, systems, subsystems, and equipment.

The calibration program is a planned, systematic schedule of actions necessary to provide confidence that equipment used to make measurements or quality judgments conforms to establish technical requirements. It ensures measurement traceability to the National Institute of Standards and Technology (NIST) or other nationally recognized standards. Measurements in the mechanical, electrical, electronics, chemical, and nuclear fields are included.

The contents of this document are reviewed and revised triennially by the calibration committee appointed by the TSS section head. The plan is distributed according to the distribution list at the end of this document.

Maintenance shops that calibrate radiation protection instrumentation governed by the Health Physics Instrument Committee (HPIC) adhere to the policies and guidelines prescribed by the HPIC. These policies and guidelines are given in the Health Physics Instrument Committee (HPIC) Radiation Protection Instrument Calibration Procedure Manual.

\subsection{Definitions}

The following definitions are provided to ensure uniform understanding of selected terms as they are used in this document.

A. Calibration: The set of operations which establishes, under specified conditions, the relationship between values indicated by a measuring instrument or measuring system and the corresponding standard or know values derived from the standard. 
B. Limited Calibration: Calibration of measuring and test equipment (M\&TE) at a level of accuracy lower than that specified in the authorized calibration procedure or M\&TE manufacturer's specifications, but acceptable for its intended use or for limited functions or ranges on a multifunctional instrument.

C. Calibration record or report: Document that presents calibration results and other information relevant to a calibration.

D. Correction table: Table of values prepared for a specific item of M\&TE to show the corrections necessary to obtain actual values.

E. Equipment Types:

1. Measuring and test equipment: M\&TE includes all tools, gauges, instruments, devices or systems used to inspect, test, calibrate, measure or troubleshoot in order to control or acquire data for verifying the conformance of an instrument or piece of equipment to specified requirements. M\&TE does not include test equipment used for preliminary checks where data obtained will not be used to determine acceptability or verify conformance to established criteria.

2. Intrinsic standard: A standard quantity derived from physical principles and natural processes which can be reproduced in a laboratory. Locally established intrinsic standards can be used to provide traceability for certain measurement quantities.

3. Reference standard: A standard, generally of the highest metrological quality available at a given location, from which measurements made at that location are derived.

4. Transfer standard: A laboratory instrument that is used to calibrate working standards and is calibrated periodically against the reference standard.

5. Working standard: An instrument that is calibrated in a laboratory against a transfer standard or laboratory standard and is used as a standard for calibrating measuring, test, or process instrumentation.

6. Equipment not requiring calibration: Equipment that does not require calibration or other comparison traceable to nationally recognized standards.

F. Custodian/User: Person or organization responsible for the use and care of a specific instrument.

G Work Centers: Maintenance shops responsible for repairing and calibrating M\&TE. 
H. Metrology: The science of measurement. In general, the application of measurement science includes knowledge of standards or measurement, measurement units, frames of reference, environmental conditions, experimental techniques, statistical analysis, and reporting of data.

I. Metrology laboratory: A facility operated by the I\&C Division, Technical Support Section which serves as the metrology laboratory and central calibration shop for the TSS calibration program.

J. Traceability: The property of a result of a measurement whereby it can be related to appropriate standards, generally national or international standards, through an unbroken clain of comparisons.

K. Measurement accuracy: A number which represents a probable range of differences between a measurement result and the true value of a quantity. This number is also referred to as the uncertainty and is determined by established statistical methods.

L. In calibration: A device is assumed to be in calibration when it has an unexpired calibration label and the device shows no signs of having been subjected to abuse or an environment that may have invalidated its calibration.

M. Calibration categories: Oak Ridge National Laboratory Standard Practice Procedure X-GP8, "Control and Calibration of Measuring and Test Equipment at ORNL," does not identify categories of equipment. It specifies that upon completion of the calibration process a calibration label (Fig. 1) indicating calibration status should be attached to the equipment. It also requires that M\&TE found to be out of calibration will be tagged and/or segregated and not used until calibrated. "Do Not Use" tags may be used to identify this M\&TE (See Fig. 2).

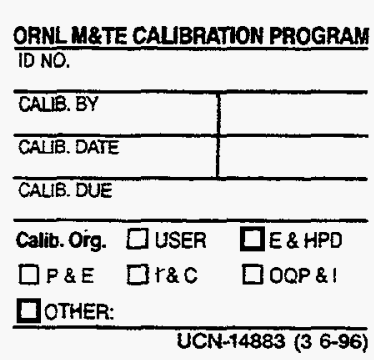

Fig. 1. Calibration status label
DO NOT USE THIS ITEM

OR REMOVE THIS TAG

'Without approval of:

Sig.:

ID\#:

CN-20187 (3 5-94) 


\section{PROGRAM ORGANIZATION}

\subsection{Overview}

The purpose of the TSS calibration plan is to provide a uniform and documented calibration program to ensure that all M\&TE used in support of ORNL systems and experiments is maintained at a high level of confidence. The plan states the basic elements of a comprehensive control and calibration program. The responsibilities of TSS calibration shops and personnel, the metrology laboratory, and the custodian/user are also identified.

\subsection{Program Policy and Direction}

This plan complies with and expands upon ORNL Standard Practice Procedure X-GP-8, which defines the requirements for effective control and calibration of M\&TE.

\subsection{Calibration Program Elements}

A comprehensive control and calibration program for M\&TE should include the following basic elements:

A. A current master equipment list that uses a unique number identification system and a computerized database for storing equipment history.

B. Calibration standards traceable to nationally recognized standards and the associated equipment and systems to maintain statistical control of the calibration process.

C. Provisions for identifying limitations in the use of M\&TE items not fully calibrated.

D. Use of documented, reviewed, and approved procedures by knowledgeable technicians.

E. Methodology for handling M\&TE determined to be out of calibration, defective, or unreliable.

F. Acquisition and control of operating and technical manuals for M\&TE.

G. Selection, maintenance, and documentation of suitable equipment necessary to maintain an effective calibration program.

H. Training for all personnel that perform calibration tasks. 


\subsection{Responsibilities}

\subsubsection{Technical Support Section}

A. Provides training to ensure that technicians performing calibrations have adequate knowledge and use approved procedures.

B. Maintains the Maintenance Accountability, Jobs, and Inventory Control (MAJIC) System, which is a part of the Maintenance Information and Data Acquisition System (MIDAS) information system. MIDAS is a database system that contains the M\&TE master equipment list, service records, and status reports and provides for scheduling of equipment on calibration recall.

C. Maintains working standards and ensures measurement traceability to NIST or other nationally recognized standards.

\subsubsection{Metrology Laboratory}

A. Maintains reference standards and ensures measurement traceability to nationally recognized standards and provides specialized services for calibration of unique equipment.

B. Provides calibration services for working and transfer standards to TSS in support of maintenance activities.

C. Provides TSS with consultation service on the development of experimental methodologies for performing maintenance and calibration activities.

D. Provides metrology engineering and measurement systems development to all ORNL division as requested.

\subsubsection{Shop Supervisor/Technical Support}
A. Assists in evaluating calibration data and prepares correction charts if necessary or requested.
B. Implements the TSS Calibration Program.
C. Reviews for adequacy and authorizes the use of manufacturers' calibration procedures when no applicable TSS procedures exist.
D. Prepares calibration procedures for M\&TE when no applicable procedures exist or when existing procedures are determined to be inadequate.


E. Updates the M\&TE master equipment list and maintains calibration records for equipment calibrated.

F. Notifies custodian/user when out-of-tolerance conditions occur.

G. Ensures that personnel performing calibrations on M\&TE are familiar with the calibration plan and that personnel training is documented in the TSS training database.

H. Ensures that "as-found" and "as-left" calibration data are documented, stored, and readily retrievable.

I. Ensures that calibration information for each calibration activity is provided to the custodian/user upon request.

J. Ensures that TSS working standards are traceable directly to nationally recognized standards.

\subsubsection{Technician}

A. Verifies that standards are within the current calibration interval and in good working condition before use.

B. Checks operational performance and records "as-found" data.

C. If "as-found" data indicate out-of-tolerance condition, adjustments are performed and "as-left" data are recorded.

D. Prepares calibration and correction charts when appropriate.

E. Shall be aware of system requirements and report any discrepancies.

F. Shall report to the facility manager and shop supervisor out-of-tolerance conditions.

\subsubsection{User/Task Leader}

The responsibilities of the User/Task Leader are defined in ORNL Standard Practice Procedure X-GP-8. 


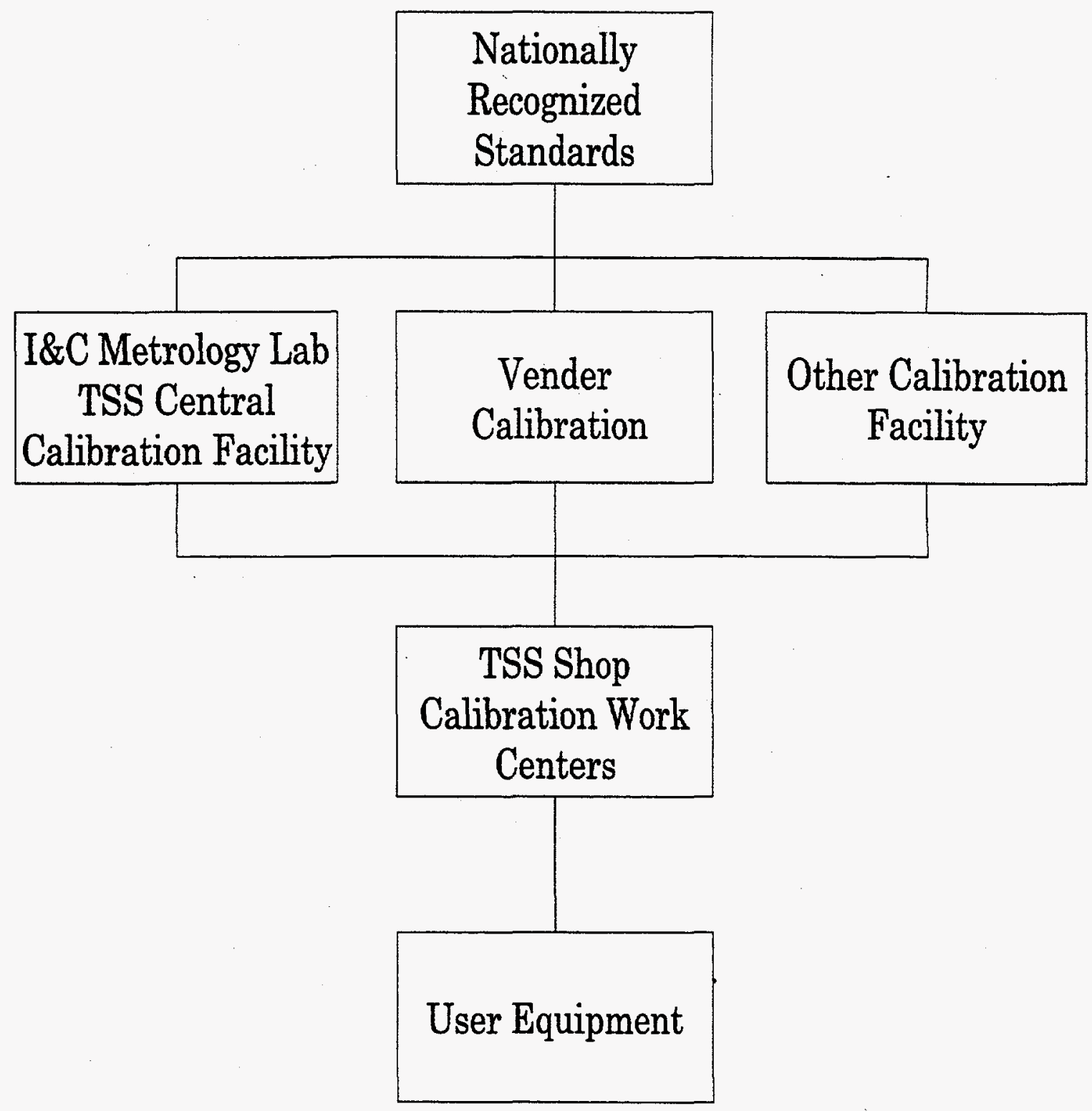

Fig. 3. Measurement traceability of the Calibration Program. 


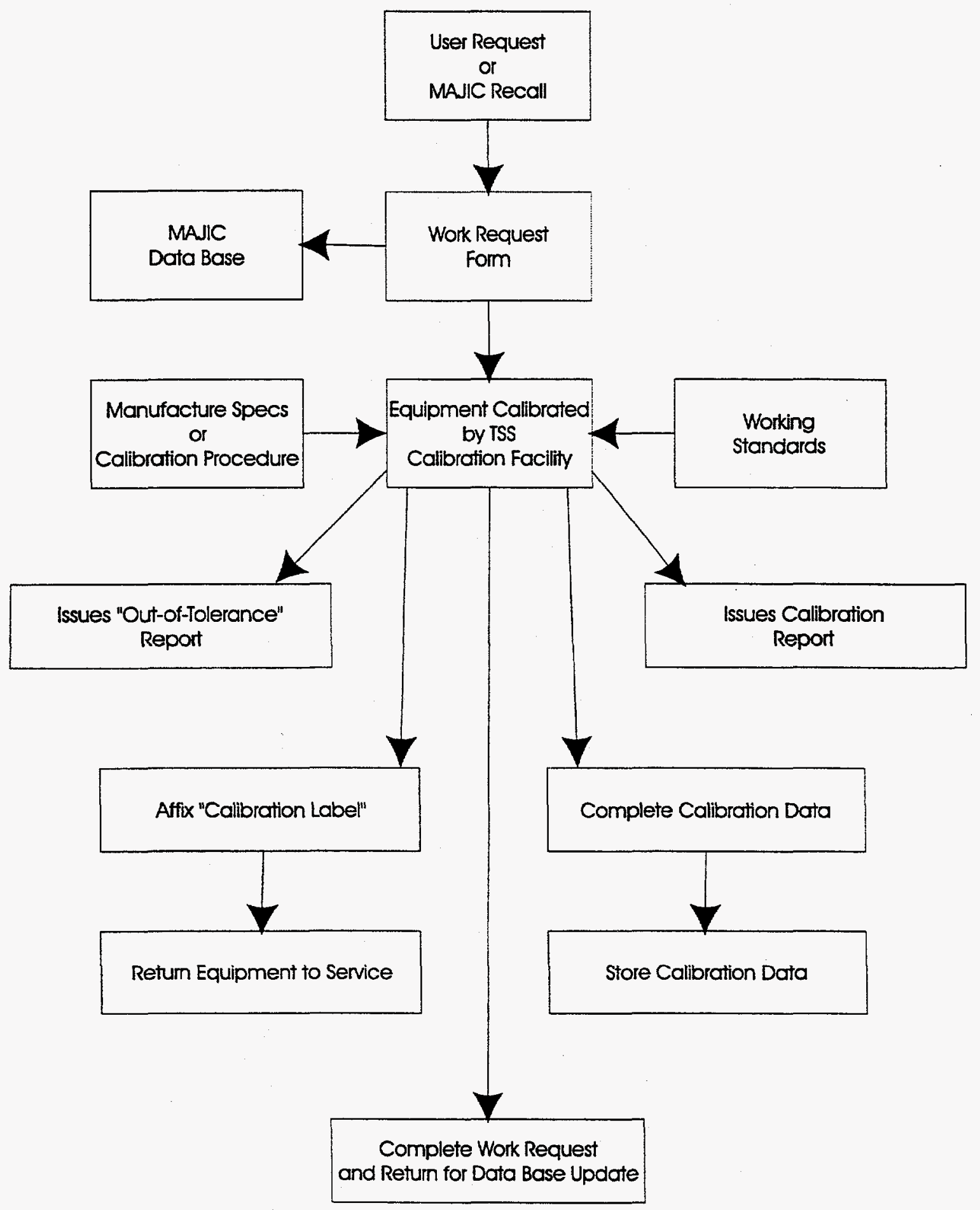

Fig. 4. Calibration job flow. 


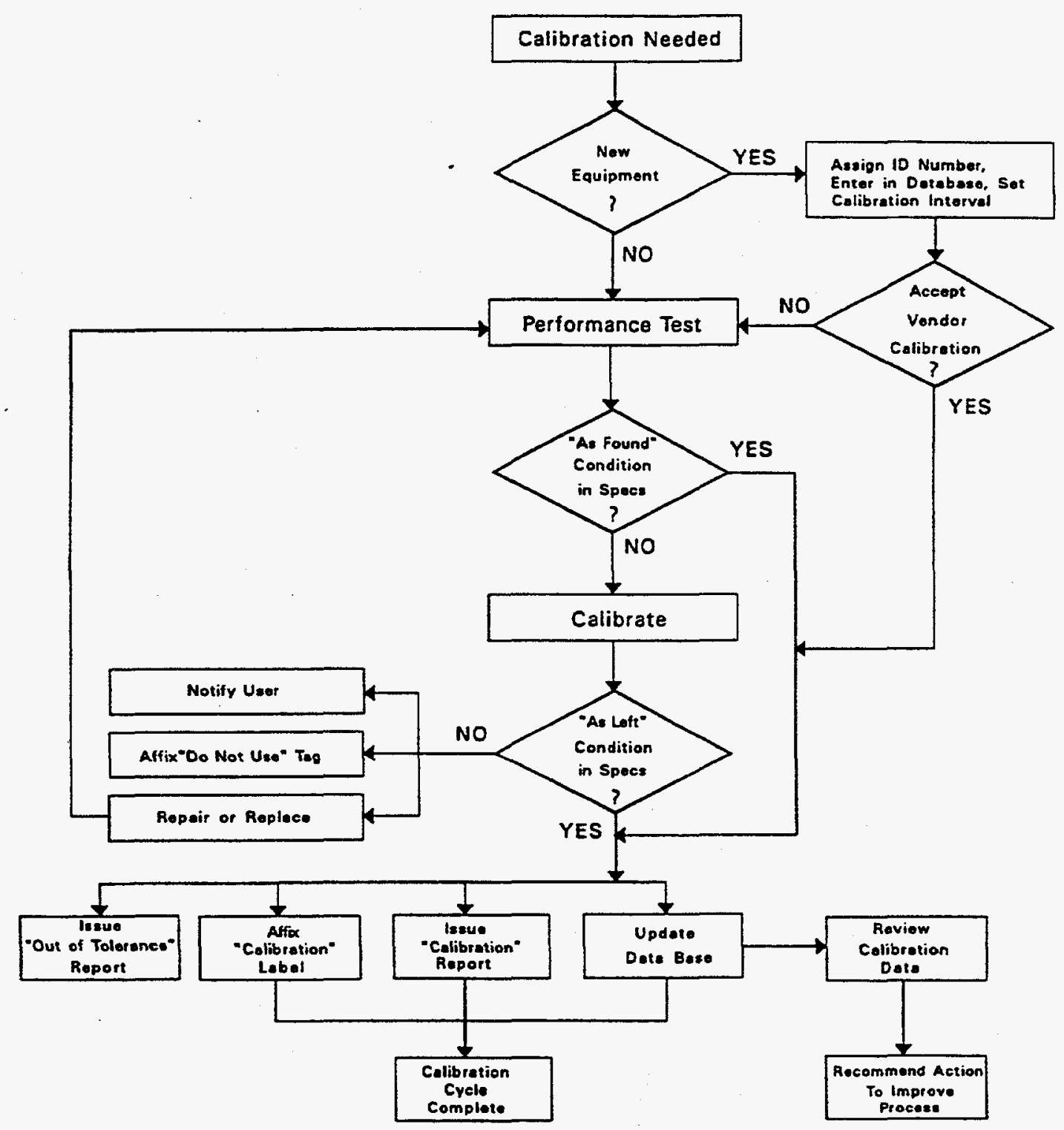

Fig. 5. Flow of the calibration process after the custodian decides that M\&TE requires calibration. 


\section{OPERATION}

\subsection{Calibration}

Maintenance shops, that are staffed and operated by the TSS are responsible for repairing and/or calibrating all M\&TE assigned to their area of responsibility. Calibration intervals and responsibilities for maintenance or calibration are identified in this document. M\&TE that is not used to make measurements critical to the test and alignment of operational systems and equipment is calibrated at specific intervals or before use.

A. To ensure a valid and accurate calibration, (1) an approved calibration procedure must be specifically referenced by (2) knowledgeable personnel using (3) equipment specified in the procedure (or adequate substitutes with required functions, ranges, and accuracies). Draft procedures may be used to perform calibrations, provided the procedures have been marked "DRAFT" and approved by the responsible TSS supervisor. Final approval of calibration procedures requires signature of the TSS department head or designee and the division Quality Assurance Officer. If no procedure is available for an M\&TE item, vendor or industry-approved general procedures will be used to calibrate the M\&TE after the procedures are reviewed for adequacy by the shop supervisor.

B. Although the maintenance supervisor is expected to assist the custodian/user in determining the extent of maintenance and required calibration to be performed, the decision to calibrate and the limits of calibration are the ultimate responsibility of the custodian/user.

C. The equipment required to calibrate an item shall be listed in the individual calibration procedure. Other approved equipment having the necessary characteristics such as functions, ranges, and accuracies may be used to perform a calibration even though that equipment may not have all the characteristics of the listed item.

D. M\&TE and calibration standards are selected to provide suitable accuracy, range, stability, and resolution to meet the requirements of the intended use. Accuracy ratios between standards and devices under test should be maintained at $4: 1$ where practical. Calibrations performed at accuracy ratios of less that $4: 1$ should employ statistical methodologies that verify that accuracy transference meets specified levels of measurement assurance.

It is important to note that good judgment must always be applied in calibrating equipment. Whether or not a piece of standard M\&TE is of adequate quality and accuracy to make reasonable measurements should be apparent to an experienced technician or supervisor. An essential criterion for calibration is that the equipment in question be sufficiently stable and accurate to perform its intended function. 


\subsection{Exceptions to Periodic Calibration Requirements}

Certain types of M\&TE do not require periodic calibration. The work center supervisor and the $M \& T E$ custodian/user are responsible for determining calibration exceptions.

A. M\&TE that is seldom used but must be calibrated before use.

B. M\&TE that requires initial calibration only.

C. M\&TE identified as "Calibration not required" (CNR) does not require calibration because it does not provide quantitative measurement information (i.e., information obtained by its use is of a gross nature such as verifying power on or off).

\subsection{Limited Calibration}

In some situations, the work center may be authorized to perform a limited calibration (see definitions, Sect. 1.2). The work center supervisor may require written authorization from the custodian/user to perform a limited calibration.

\subsubsection{Limited Shop Capability}

When a work center does not have the capability to calibrate the full range of specifications contained in the calibration procedure, the work center supervisor shall advise the custodian/user of the extent of available services. The custodian/user shall then determine whether the available services meet measurement needs. If the limited calibration services will not meet the needs, the custodian/user shall advise the work center, and action shall be taken to obtain the necessary capabilities.

\subsubsection{Limited User Requirements}

When a user requires less than the full capability of the instrument, the user shall specify the desired calibration points or ranges to the responsible work center. The work center supervisor or calibration technician shall clearly identify the points or ranges on the calibration record and shall provide a copy of the calibration data to the custodian/user unless otherwise directed. 


\subsubsection{Instrument Limitation}

When a function, range, or specification of a multifunction instrument cannot be economically restored to its original design specifications, the work center supervisor shall advise the custodian/user of the condition. The custodian/user shall then determine whether the missing function is necessary and whether to permit a limited calibration or to replace the item. In any case, on the calibration label, check the "other" box in addition to the I\&C box and in the blank space at the bottom of the label, write "LIMITED CAL" if the calibration is limited in any way.

\subsection{Calibration Intervals}

The established interval is determined by the length of time the equipment should maintain its accuracy and perform its intended function. These intervals are established and modified as necessary.

A. The maximum calibration interval for new M\&TE is 12 months if no interval is recommended by the manufacturer. A calibration interval may be changed as a result of activity, applications, or maintenance history. Recall may be staggered to maintain an even work load in the work center. Users may request shorter intervals between calibration to meet system or project requirements.

B. Custodians/users may request recalibration any time there is reason to question the accuracy of an instrument. Items that have been exposed to rough handling, overload, or other severe conditions shall be immediately identified and recalibrated before further use, regardless of the scheduled calibration date.

C. Calibration intervals for safety instruments are identified in their respective safety documents.

\subsection{Calibration Grace Period}

The calibration of equipment shall be performed in accordance with a predetermined schedule. Extensions to the interval of up to 30 days may be given. If the grace period is preempted by a DOE order, law, safety document, or regulation, the exception shall be documented and the new requirements defined. Grace periods for safety instruments are defined in their respective safety documents. 


\subsection{Calibration Deviations}

The Deviation Request, Form UCN-5458A, shall be completed in accordance with instructions on the back of the form for the following situations:

A. The instrument is removed from calibration recall by the custodian/user:

B. The instrument calibration is refused by custodian/user but instrument is not to be removed from recall system:

C. The calibration period is extended as a result of workload considerations and/or the equipment is unavailable at the scheduled recall date.

The work center supervisor shall:

A. complete the Deviation Request form;

B. file a copy of the completed form at the work center and submit a copy to the custodian/user for signature; and

C. upon receipt of the signed copy from the custodian/user, replace the file copy with the signed copy.

\subsection{Care of Measuring and Test Equipment}

Custodians/users are responsible for the proper handling, storage, care, use, and cleanliness of M\&TE.

A. Items of M\&TE shall be handled in such a way as to protect the condition and integrity of equipment regardless of its physical appearance.

B. It is the responsibility of the custodian/user to ensure that M\&TE is properly cleaned and tagged to indicate freedom from all contamination before transport to the responsible work center.

C. Calibration work centers shall tag or segregate out-of-calibration M\&TE to prevent its unauthorized use. 


\subsection{Measuring and Test Equipment Warranties}

M\&TE is frequently covered by a provisional warranty from the manufacturer. Such warranties vary in length of coverage and specific service or maintenance coverage as well as in provision for correction of deficiencies in design, material, or workmanship that does not meet M\&TE performance specifications.

A. The work center supervisor is authorized to use the manufacturer's calibration certification on new M\&TE to establish the first calibration cycle and shall affix a calibration label, provided it can be verified that the device was in acceptable condition when received and put into service.

B. Upon receipt of new equipment, the work center shall

1. determine the warranty expiration date,

2. calibrate equipment if required, and

3. return defective equipment under warranty to the custodian/user with technical information relative to the defect or return to the vendor for warranty repair. 


\section{CALIBRATION LABELS AND FORMS}

\subsection{Preparation and Use of Calibration Forms and Labels}

All instruments for which the TSS has calibration responsibility shall be
A. identified with a unique identification number,
B. recorded in the MIDAS inventory, and
C. labeled with a calibration label filled out in ink, which will withstand the effect of the operating environment to which it will be subjected.

Note that under no circumstances shall information on calibration labels be altered. When a change in label information is required, remove and destroy the old label and affix a new label that displays the proper information.

\subsection{Measuring and Test Equipment Calibration Label}

The calibration label (UCN-14883) shown in Fig. 1 shall be completed and affixed to standards and M\&TE calibrated by the responsible work center. If the labels or tags are not practical, a facility logbook, technical notebook, or report of instrument calibrated may be used to record calibration status. The calibration technician shall complete the label in non-smearing permanent ink as follows:

A. Identification number: Enter the identification (ID) number recorded in the MIDAS system on the equipment calibrated.

B. Date: Enter the date the M\&TE was calibrated. When authorized to use the manufacturer's calibration, use the date on the manufacturer's certificate rather than the date the unit was placed into service.

C. Calibrated by: Enter badge number of the calibration technician in this block. The I\&C calibration technician shall enter a check in the block that appropriately identifies the work center.

D. Calibration due: Enter the month and year in which the equipment is due for calibration. The calibration due date shall be obtained from the calibration work request or computed from the assigned calibration interval and start month on the instrument inventory. Items calibrated and not on program recall shall be marked "NONE." 


\subsection{Placement of Calibration Labels}

Calibration labels shall be affixed to a clean surface in a conspicuous area on the equipment. On small items, the label may be affixed to a tag and displayed by hanging on the equipment in an obvious and secure fashion, or the label may be placed in a container or cabinet that evidences the label and its association with the specific item being identified. The calibration label may be affixed to the side or back panel of interchangeable plug-ins. If the label cannot be placed on the front panel or if a tag would interfere with the operation of the plug-in, the size of the tag may be reduced by trimming. Trimmed tags must continue to display the ID number and recall date. All outdated labels shall be removed. On complex M\&TE such as test stands and checkout consoles, one calibration label for the end item will suffice for all items that are integral parts of the equipment.

\subsection{Calibration Record}

The I\&C calibration record (UCN-10600, Fig. 6) data sheet or calibration table on the IDS shall be completed for M\&TE calibrated by the work center technician to show the actual values of the parameters checked. The work center shall store and be able to retrieve the calibration record, and a copy may be attached to the equipment. The calibration record shall be in ink, legible, neat, and unaltered (no correction fluid). Errors should have a line drawn through, be initialed, and have correct data written in.
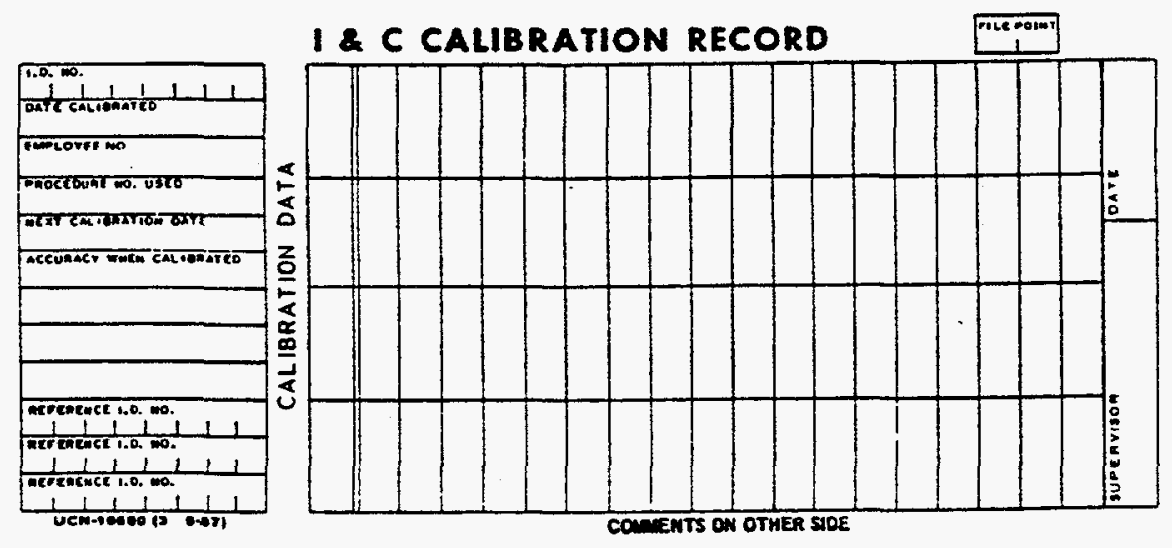

Fig. 6. Calibraton record (UCN-10600). 
The calibration record or data sheet shall contain the following information:

A. Identification number assigned to the $M \& T E$,

B. Date on which the M\&TE was calibrated,

C. The badge number of the calibration technician,

D. The calibration procedure number assigned to the M\&TE,

E. The next calibration due date, determined by the assigned calibration interval as described in item $\mathrm{D}$ of Sec. 4.2. Items calibrated and not on program recall shall be marked "NONE."

F. Accuracy when calibrated shall meet the manufacturer's specifications unless otherwise noted. For limited calibrations, identify the parameter(s) calibrated and accuracy required.

G. Record the ID number(s) of the standard(s) used to perform the calibration.

$\mathrm{H}$. When recording the calibration data, indicate appropriate column headings and units for the calibration parameters. Recorded information shall include "as-found" and "asleft" data as well as errors calculated.

I. The work request number (IDS\#) shall appear on the calibration record/data sheet.

The technician performing the calibration shall sign and date the calibration record or data sheet after the calibration is completed, and the supervisor or designated representative will review for completeness, sign, and file.

When calibration data cannot be entered on the I\&C calibration record or data sheet, all other pertinent information shall be entered with a note across the data entry indicating the location of the calibration data. (May be utilized for computerized/electronically stored data.)

NOTE: If the calibration record (UCN-10600) is used, enter the work request number for the job in the space above the M\&TE ID number.

\subsection{Calibration Correction Record}

A chart or graph shall be made available, when requested by the using organization, to show the correction that must be applied to the indicated reading to obtain the actual value. 


\section{CALIBRATION REPORTS}

The TSS MAJC system collects maintenance data on M\&TE selected for calibration recall and provides computer-generated reports for control. Reports are available to identify current custodian, location of equipment, calibration interval, and next recall date. 


\section{INTERNAL DISTRIBUTION}

1.

2.

$3-12$.

13.

14.

15.

16.

17.

18.

19.

20.

21.

22.

23. J. L. Hammontree

24. J. M. Jansen

25. M. Kreiger
26.

27.

28.

29

30.

31.

32.

33.

34.

35.

36.

37.

38-39.

40.
D. W. McDonald

T. J. McKnight

L. E. McNeese

G. N. Miller

J. E. Payne

D. G. Prater

W. L. Robbins

C. S. Sims

H. E. Smith

J. D. White

ORNL QA Manager

Central Research Library

Laboratory Records - OSTI

Laboratory Records M-RC

\section{EXTERNAL DISTRIBUTION}

41. Edward Cumesty, Assistant Manager for Laboratories, DOE-ORO, P.O. Box 2001, Oak Ridge, TN 37831-8600

42. Ronald O. Hultgren, ORNL Site Manager, DOE-ORO, ORNL Building 4500N, Room 211, MS 6269 (or P.O. Box 2008, Oak Ridge, TN 37831-6269)

43. Michele G. Branton, ORNL Maintenance Program Manager, DOE-ORO, ORNL Building 4500N, Room 231, MS 6269 (or P.O. Box 2008, Oak Ridge, TN 37831-6269)

44-46. D. C. Queen, DOE-ORO, Y-12 Plant, Building 9114, Oak Ridge, TN 37831-8722

47. Ron Moore, The RM Group, Inc., 12024 Broadwood Drive, Knoxville, TN 37922

48. David Norton, Houston Advanced Research Center, 4800 Research Forest Dr., The Woodlands, TX 77381

49. Robert M. Taylor, Leeds and Northup, Sunneytown Pike, North Wales, PA 19454

50. M. M. Sevik, Caderock Division, Naval Surface Warfare Center, Code 70, Bethesda, MD 20084-5000

51. Ernesto Suarez, Pratt \& Whitney, P.O. Box 109600, MS 617-87, W. Palm Beach, FL $33410-9600$ 